\title{
Analysis of ovarian teratomas for isochromosome 12p: evidence supporting a dual histogenetic pathway for teratomatous elements
}

\author{
Christopher Poulos ${ }^{1}$, Liang Cheng ${ }^{1}$, Shaobo Zhang ${ }^{1}$, Deborah J Gersell ${ }^{2}$ and \\ Thomas M Ulbright ${ }^{1}$
}

${ }^{1}$ Department of Pathology, Indiana University School of Medicine, Indianapolis, IN, USA and ${ }^{2}$ Department of Pathology, St John's Mercy Medical Center, St Louis, MO, USA

\begin{abstract}
Teratomas are the most common germ cell tumor (GCT) of the ovary and include several types with a range of clinical behavior. As in testicular teratomas, they may be benign, malignant or a component of a mixed GCT. In the testis, data support separate pathogeneses for prepubertal and postpubertal teratomas, with derivation of the former from a nontransformed germ cell and the latter from differentiation of a nonteratomatous, malignant GCT. The absence of cytogenetic abnormalities (including isochromosome 12p (i(12p)) in mature ovarian teratomas suggests that they may be analogous to prepubertal testicular teratomas, but there are no data regarding genetic changes in the teratomatous components of ovarian mixed GCTs. We therefore studied the teratomatous components of six mixed GCTs of the ovary using fluorescence in situ hybridization (FISH) for i(12p). Six mixed GCTs of the ovary occurred in patients 4-33 years of age; all had teratomatous and yolk sac tumor components and three also contained foci of embryonal carcinoma. Using FISH with $12 p$ telomeric and 12 centromeric probes, five of six $(83 \%)$ cases had detectable $i(12 p)$ in their nonteratomatous components, and four of six $(66 \%)$ in the teratomatous component. One of the two cases without demonstrable $i(12 \mathrm{p})$ in the teratomatous portion of the mixed GCT also did not have identifiable 12p abnormalities in other elements of the mixed GCT. By comparison, five pure, mature ovarian teratomas and three pure, immature ovarian teratomas showed no evidence of either $i(12 p)$ or other forms of $12 p$ amplification. These findings support that teratoma in mixed ovarian GCTs has a different pathogenesis compared to pure teratoma of the ovary. Furthermore, the findings of $i(12 p)$ in both the teratomatous and nonteratomatous components of ovarian mixed GCTs supports that the teratoma derives from other components, similar to the situation in the testis.
\end{abstract}

Modern Pathology (2006) 19, 766-771. doi:10.1038/modpathol.3800596; published online 17 March 2006

Keywords: FISH; histogenesis; isochromosome 12p; mixed germ cell tumor; ovarian neoplasms; teratoma

Ovarian teratomas include several types that exhibit varying clinical behavior; the majority are benign, pure, mature, and cystic. ${ }^{1,2}$ Malignant forms include immature teratomas, teratomas with malignant transformation (also designated 'somatic-type tumors' with dermoid cysts), and teratomatous components of mixed germ cell tumors (GCTs). Immature teratomas are much less frequent than their

Correspondence: Dr TM Ulbright, MD, Department of Pathology, Indiana University Hospital, Room 3465, 550 N. University Blvd., Indianapolis, IN 46202-5280, USA.

E-mail: tulbrigh@iupui.edu

Presented in part at the 94th meeting of the United States and Canadian Academy of Pathology, 28 February 2005, San Antonio, TX, USA

Received 29 December 2005; revised and accepted 28 February 2006; published online 17 March 2006 mature counterparts, tend to occur in younger patients, often are solid, and, by definition, have malignant, immature tissue, usually neuroepithelium. ${ }^{2-5}$ Teratomas with malignant transformation usually occur in older women, most often contain squamous cell carcinoma, and are rare, accounting for only $1-2 \%$ of teratomas. ${ }^{2,6,7}$ Mixed GCTs are another rare subset of ovarian GCTs and may be composed of a mixture of mature teratoma, immature teratoma, dysgerminoma, yolk sac tumor, and embryonal carcinoma. ${ }^{8}$ To date, there are limited data regarding the origins of these different forms of ovarian GCT, except for mature teratoma where a parthenogenetic-like mechanism is supported based, in part, on homozygosity for polymorphic markers. ${ }^{9,10}$ How teratomatous elements develop in mixed ovarian GCTs, however, is currently 
unknown, although there may be parallels with the situation in the testis.

In the testis, data support separate pathogeneses for prepubertal and postpubertal teratoma, namely derivation of the former from a benign, nontransformed germ cell and the latter from differentiation of a nonteratomatous, malignant GCT. ${ }^{2}$ There may be comparable differences between the origin of pure ovarian teratomas and the origin of the teratomatous components of ovarian mixed GCTs, but there are no available data regarding cytogenetic changes in the teratomatous components of mixed GCTs of the ovary. It was our hypothesis that these tissues derive from the nonteratomatous components analogous to postpubertal testicular teratomas, and should, therefore, have similar cytogenetic abnormalities. Since ovarian GCTs have been shown to have isochromosome $12 p(i(12 p))$ and $12 p$ amplification, ${ }^{11,12}$ the demonstration of $i(12 p)$ in the teratomatous components of mixed GCTs of the ovary would support this hypothesis. This study, therefore, examines the origin of ovarian teratomas by using fluorescence in situ hybridization (FISH) to look for $\mathrm{i}(12 \mathrm{p})$ and $12 \mathrm{p}$ amplification in the teratomatous components of mixed GCTs, with comparison to findings in mature and immature teratomas.

\section{Materials and methods}

\section{Specimens}

We analyzed a total of 14 ovarian GCTs using FISH. Six patients whose ages at the time of diagnosis ranged from 4 to 33 years (mean, 18 years) had mixed GCTs. Each of these contained mature teratoma that was admixed with various combinations of other GCT elements including embryonal carcinoma, yolk sac tumor, and immature teratoma (Figure 1) (Table 1). These were compared to eight pure teratomas (five mature (Figure 2), three im-

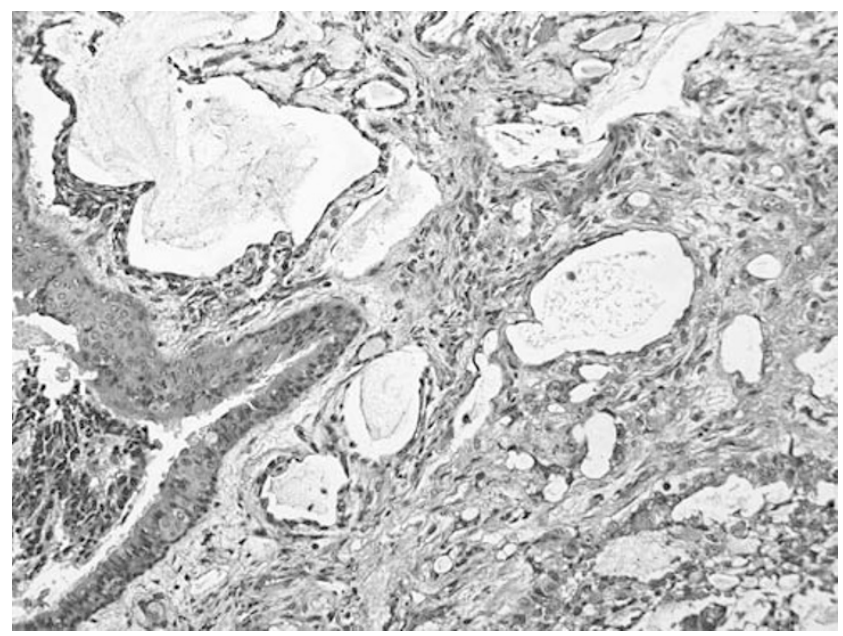

Figure 1 Ovarian mixed germ cell tumor showing a teratomatous component of respiratory epithelium (left) with yolk sac tumor. mature) in patients ranging from 20 to 75 years old (Table 1); none showed 'malignant transformation'.

\section{Fluorescent In Situ Hybridization}

From each specimen, multiple $4 \mu \mathrm{m}$ unstained sections were prepared from buffered formalinfixed, paraffin-embedded tissue blocks. A hematoxylin and eosin stained slide from each case was examined to determine the area of different tumor components.

FISH was performed using previously reported methods. ${ }^{13}$ The slides were deparaffinized with two

Table 1 The presence of $i(12 p)$ and $12 p$ amplification in mixed germ cell tumors and pure teratomas of the ovary

\begin{tabular}{|c|c|c|c|c|}
\hline Case & $\begin{array}{c}\text { Age } \\
\text { (years) }\end{array}$ & GCT component & $\begin{array}{c}12 p \\
\text { amplification }\end{array}$ & $i(12 p)$ \\
\hline \multirow[t]{3}{*}{1} & 4 & Mature teratoma & - & - \\
\hline & & Embryonal carcinoma & + & + \\
\hline & & Yolk sac tumor & + & + \\
\hline \multirow{3}{*}{2} & 10 & Mature teratoma & - & - \\
\hline & & Immature teratoma & + & + \\
\hline & & Yolk sac tumor & - & + \\
\hline \multirow[t]{3}{*}{3} & 33 & Mature teratoma & - & - \\
\hline & & Embryonal carcinoma & - & - \\
\hline & & Yolk sac tumor & - & - \\
\hline \multirow[t]{2}{*}{4} & 24 & Mature teratoma & - & + \\
\hline & & Yolk sac tumor & + & + \\
\hline \multirow[t]{3}{*}{5} & 14 & Teratoma & - & + \\
\hline & & Embryonal carcinoma & - & - \\
\hline & & Yolk sac tumor & - & + \\
\hline \multirow{2}{*}{6} & 23 & Teratoma & - & + \\
\hline & & Yolk sac tumor & - & + \\
\hline 7 & 20 & Mature teratoma & - & - \\
\hline 8 & 36 & Mature teratoma & - & - \\
\hline 9 & 60 & Mature teratoma & - & - \\
\hline 10 & 75 & Mature teratoma & - & - \\
\hline 11 & 47 & Mature teratoma & - & - \\
\hline 12 & 21 & Immature teratoma & - & - \\
\hline 13 & 30 & Immature teratoma & - & - \\
\hline 14 & 32 & Immature teratoma & - & - \\
\hline
\end{tabular}

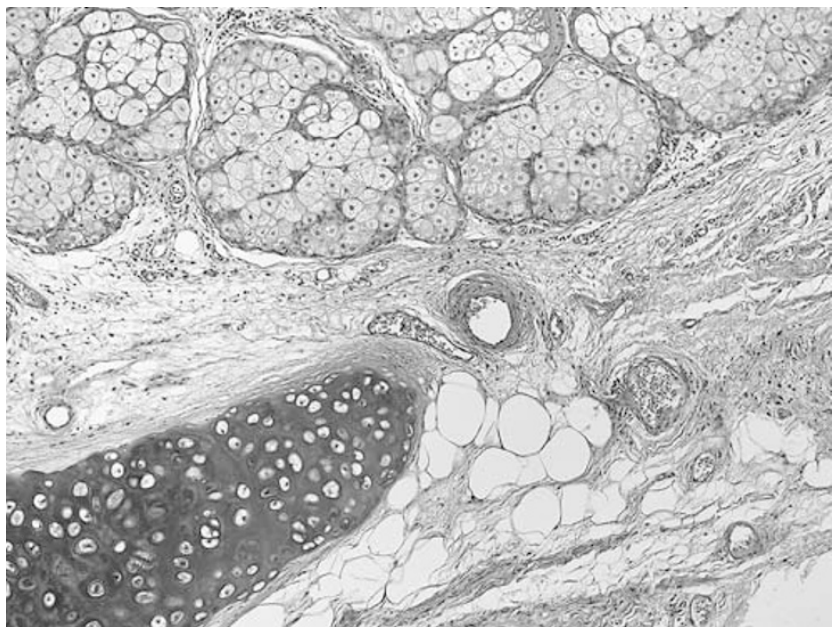

Figure 2 Mature teratoma with sebaceous glands and cartilage. 
washes of xylene, $15 \mathrm{~min}$ for each and were subsequently washed twice with absolute ethanol, $10 \mathrm{~min}$ each. The slides were rinsed with distilled water for 3 min and further washed with $2 \times$ standard saline citrate (SSC) for $5 \mathrm{~min}$ and allowed to air dry in a hood. Next, the slides were treated in $0.1 \mathrm{mM}$ citric buffer (pH 6.0) (Zymed, CA, USA) at $95^{\circ} \mathrm{C}$ for $10 \mathrm{~min}$, rinsed in distilled water for $3 \mathrm{~min}$, followed by a wash of $2 \times$ SSC for $5 \mathrm{~min}$. Digestion of the tissue was performed by applying $0.4 \mathrm{ml}$ of pepsin ( $5 \mathrm{mg} / \mathrm{ml}$ in $0.9 \% \mathrm{NaCl}$, pH 1.5) (Sigma, St Louis, $\mathrm{MO}$, USA) at $37^{\circ} \mathrm{C}$ for $40 \mathrm{~min}$. The slides were then washed with distilled water for $3 \mathrm{~min}$ and further washed with $2 \times$ SSC for 5 min and air-dried. Dualcolor FISH was performed by using a mixture of a Spectrum orange-labeled centromeric $\alpha$-satellite DNA probe (CEP12) and a Spectrum green-labeled subtelomeric (Tel12) DNA probe for chromosome 12p. Both of the probes were from Vysis (Vysis, Downers Grove, IL, USA) and were diluted with tDenHyb2 (Insitus, Alburquerque, NM, USA) in a ratio of 1:50 and 1:20, respectively. Diluted probes, $5 \mu \mathrm{l}$, were added to the slide in reduced light conditions, and each slide was covered with a $22 \times 22$ cover slip and the edges were sealed with rubber cement. Denaturation was achieved by incubating the slides at $75^{\circ} \mathrm{C}$ for $10 \mathrm{~min}$ in a humidified box and then hybridized at $37^{\circ} \mathrm{C}$ overnight.

After hybridization the slides were washed with $45^{\circ} \mathrm{C}$ prewarmed $0.1 \times \mathrm{SSC} / 1.5 \mathrm{M}$ urea twice, $20 \mathrm{~min}$ for each, followed by a wash with $2 \times$ SSC for $20 \mathrm{~min}$ and $2 \times \mathrm{SSC} / 0.1 \% \mathrm{NP} 40$ for $10 \mathrm{~min}$ at $45^{\circ} \mathrm{C}$. The slides were further washed with $2 \times$ SSC at room temperature for $5 \mathrm{~min}$, air dried, counterstained with $10 \mu \mathrm{l}$ DAPI (Insitus, Albuquerque, NM, USA) and covered and sealed with nail polish.

The slides were examined using a Zeiss Axioplan 2 microscope (Zeiss, Göttingen, Germany) with the following filters: SP-100 DAPI, FITC MF-101 for spectrum green (12p) and Gold 31003 for Spectrum orange (CEP12) from Chroma (Chroma, Brattleboro, VT, USA). For each case up to 20 fields were captured under a $100 \times$ oil objective. The images were acquired with a CCD camera and analyzed with MetaSystem Isis software (MetaSystem, Belmont, MA, USA). Five sequential focus stacks with $0.4 \mu \mathrm{m}$ interval were acquired and then integrated into a single image in order to reduce thickness related artefacts. Criteria for the signal detection were described previously. ${ }^{14-16}$ Fifty to 200 cells were counted for each of the components. Classic seminoma of the testis was used as a positive control.

\section{Results}

Either i(12p) (Figure 3) or 12p amplification (Figure 4) was observed in five of 14 cases examined
(Table 1). None of the pure mature or immature teratomas displayed either $\mathrm{i}(12 \mathrm{p})$ or $12 \mathrm{p}$ amplification as defined by a $12 \mathrm{p} / 12$ centromeric ratio of 1.5 or greater. In the pure mature and immature teratomas, the $12 p$ portion of the chromosome was present in a ratio of $0.96-1.06$ times the centromeric portion (mean, 1). Four of six mixed GCTs had i(12p) in the teratomatous components and five of the same cases had $\mathrm{i}(12 \mathrm{p})$ in the nonteratomatous component (Table 1). In the teratomatous components of the mixed GCTs, the $12 p$ portion of the chromosome was present in a ratio of 1.01 to 1.26 times the centromeric portion (mean, 1.2). In the nonteratomatous components of the malignant GCTs, the 12p portion of the chromosome was present in a ratio of 1.03-1.68 times the centromeric portion (mean, 1.3). One of two cases that did not display $12 p$ abnormalities in the teratomatous portion of the mixed GCT also did not demonstrate them in other elements of the mixed GCT. In the teratomatous areas of the sixth case, the foci of teratoma had 12p amplified to 1.26 times the centromeric portion, which was below the cutoff value for amplification but well above the range found in the pure teratomas (0.961.06). The positive control did show $\mathrm{i}(12 \mathrm{p})$ and evidence of $12 p$ amplification, with a $12 p$ to centromeric signal ratio of 1.52 .

\section{Discussion}

Study of prepubertal and postpubertal testicular teratomas supports their separate pathogenesis, with the former deriving from a benign germ cell and the latter from a nonteratomatous malignant GCT. ${ }^{2,17}$ In this model, virtually all adult testicular teratomas are initially a component of a mixed GCT, and the occasional pure teratoma of the adult testis mostly represents the persistence of teratoma with spontaneous regression of other GCT types. Evidence supporting the origin of postpubertal testicular teratomas and the teratomatous components of mixed GCTs of the testis from malignant germ cells includes their association with intratubular germ cell neoplasia, unclassified (IGCNU),${ }^{18}$ the presence of $i(12 p)$ and of chromosome 12p amplification in both teratomatous and nonteratomatous components of postpubertal GCTs,${ }^{19-23}$ the presence of aneuploidy in postpubertal teratomas, ${ }^{22,24}$ the similarities in allelic losses between mature teratoma and other components of malignant mixed GCTs of the testis, ${ }^{25}$ the malignant behavior of postpubertal testicular teratomas, ${ }^{26-28}$ and the atypical cytologic appearance of some postpubertal testicular teratomas. $^{2,17}$ Conversely, evidence supporting the origin of prepubertal testicular teratomas from benign germ cells includes a lack of chromosome 12p amplification, ${ }^{29}$ a generally diploid, 46 XY karyotype, ${ }^{30}$ normal findings on comparative genomic hybridization studies, ${ }^{31}$ and lack of IGCNU. ${ }^{18}$ It is also well established that most ovarian teratomas derive from 

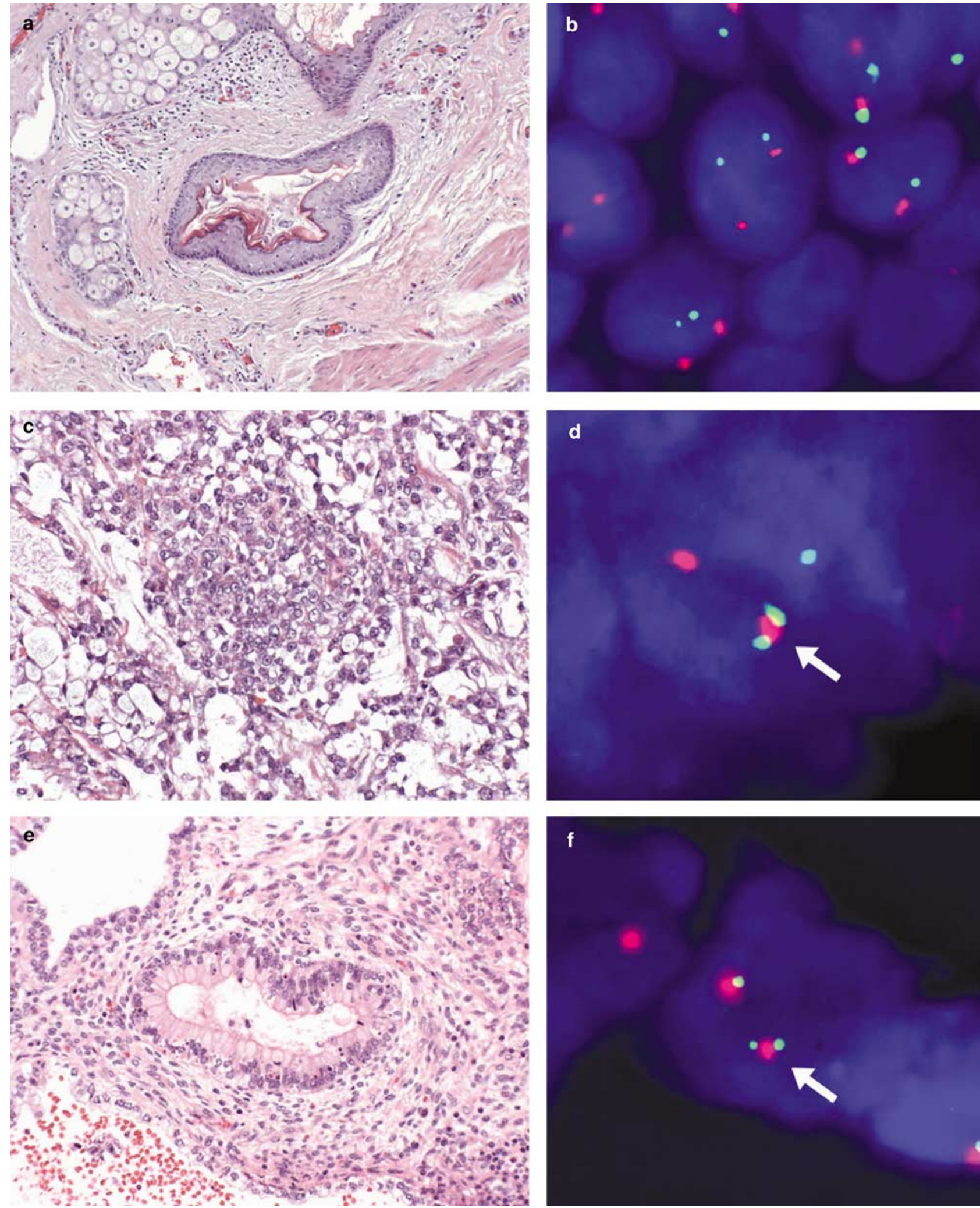

Figure 3 (a) Mature teratoma. (b) Correlating FISH of the tumor shown in (a) with normally distributed 12p telomere (green) and 12 centromere (red) signals. (c) Yolk sac tumor component from a mixed ovarian germ cell. (d) Correlating FISH of the tumor shown in (c) with close juxtaposition of 12p telomere signals (green) with 12 centromere signal (red), indicating i(12p) (arrow). (e) Teratoma in mixed germ cell tumor. (f) Correlating FISH of the teratoma shown in (e) demonstrating i(12p). 
770
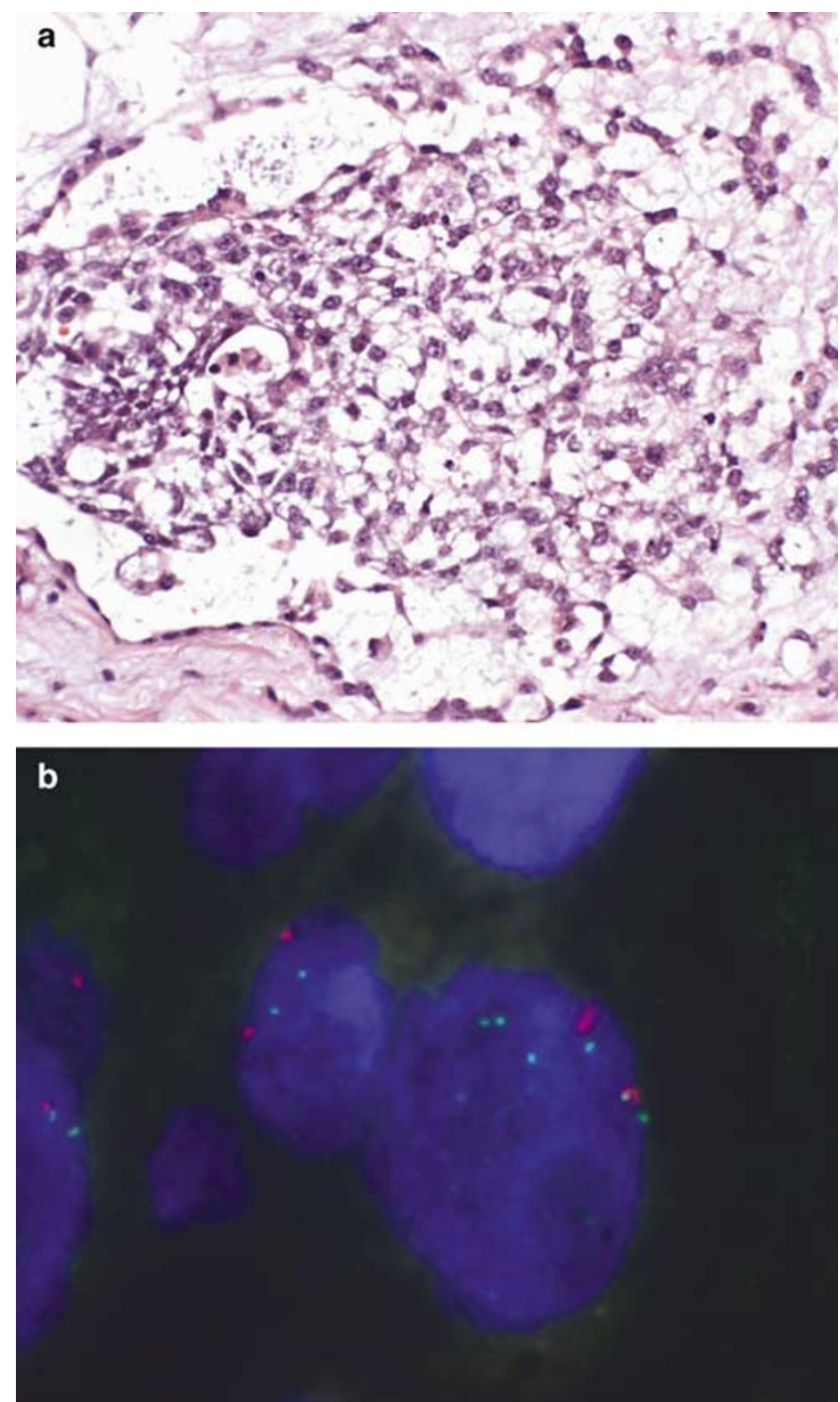

Figure 4 (a) Yolk sac tumor component of a mixed germ cell tumor. (b) Correlating FISH of the tumor shown in (a) demonstrating $12 \mathrm{p}$ amplification (green signals $-12 \mathrm{p}$ telomere; red signals12 centromere).

benign germ cells in a parthenogenetic-like fashion based on their cytogenetics, ${ }^{11,12}$ ploidy, ${ }^{32}$ and molecular biologic findings. ${ }^{10}$ In contrast to most testicular teratomas, they lack karyotypic abnormalities, including $\mathrm{i}(12 \mathrm{p})$, but have a normal, 46, XX karyotype, ${ }^{11,33}$ contain a diploid amount of DNA, ${ }^{32}$ and show a homozygous pattern for polymorphic markers. ${ }^{9,10}$ The latter observation suggests a parthenogenetic-type origin from a germ cell between meiosis I and meiosis II. A second ovarian pathway, analogous to the predominant pathway in the testis, is less well founded. We hypothesized that the teratomatous components of mixed GCTs of the ovary would have a pathogenesis similar to that of postpubertal testicular teratoma ${ }^{2,17}$ and anticipated that they would show $12 \mathrm{p}$ abnormalities similar to those found in nonteratomatous malignant GCTs of the ovary.
Our results support that the teratomatous components of mixed GCTs of the ovary have a different pathogenesis from pure mature and immature ovarian teratomas and likely derive from the nonteratomatous components of such tumors. Of cases of ovarian mixed GCT, $83 \%$ had $\mathrm{i}(12 \mathrm{p})$ in their nonteratomatous components and $66 \%$ in their teratomatous components, whereas all cases of pure mature cystic teratoma and immature teratoma lacked $i(12 p)$ or other evidence of 12p amplification. These findings parallel the presence of $i(12 p)$ and other forms of $12 p$ amplification in postpubertal testicular teratomas ${ }^{19-23}$ and the absence of such genetic findings in prepubertal testicular teratomas. ${ }^{29-31}$ Additionally, the finding of $12 p$ amplification in both the teratomatous and nonteratomatous components of ovarian mixed GCTs supports the origin of the former from the latter.

The findings of this study are in general agreement with those of others who examined the genetics of ovarian GCTs. Baker et $a l^{32}$ found that nine of 11 immature teratomas were diploid (with the two immature teratomas classified as aneuploid later being found to contain other GCT elements) and the majority of other GCT subtypes were aneuploid, with a mean DNA index of 1.85, the latter result similar to that found in adult testicular GCTs. Kraggerud et $a l^{11}$ examined 25 ovarian GCTs, finding gains of $12 \mathrm{p}$ in $67 \%$ of dygerminomas and in $75 \%$ of yolk sac tumors; however, no gain of $12 p$ was found in 11 immature teratomas. A single mixed ovarian GCT showed similar chromosomal abnormalities (including two copies of $i(12 p)$ ) to those of adult testicular GCTs. ${ }^{12}$ All of these studies collectively support a similar histogenesis for malignant ovarian GCTs and testicular GCTs, with a separate mechanism for the pure teratomas of the ovary. These results are in line with our findings.

In conclusion, we identified the frequent presence of $i(12 p)$ in the teratomatous and nonteratomatous components of ovarian mixed GCTs and its absence, as well as other evidence of $12 p$ amplification, in mature cystic ovarian teratomas and in immature ovarian teratomas. The data therefore support two pathogenetic models for ovarian teratomas: the major pathway, similar to that of prepubertal testicular teratomas, is followed by pure mature and immature teratomas and represents derivation from nontransformed germ cells; the second, minor pathway, similar to that of postpubertal testicular teratomas, is followed by the teratomatous components of mixed GCTs, with their derivation from associated nonteratomatous components.

\section{References}

1 Comerci JT, Licciardi F, Bergh PA, et al. Mature cystic teratoma: a clinicopathologic evaluation of 517 cases and review of the literature. Obstet Gynecol 1994; 84:22-28. 
2 Ulbright TM. Gonadal teratomas a review and speculation. Adv Anat Pathol 2004;11:10-23.

3 Thurlbeck WM, Scully RE. Solid teratoma of the ovary: a clinicopathologic analysis of 9 cases. Cancer 1960; 13:804-811.

4 Norris HJ, Zirkin HJ, Benson WL. Immature (malignant) teratoma of the ovary: a clinical and pathologic study of 58 cases. Cancer 1976;37:2359-2372.

5 Nogales Jr FF, Favara BE, Major FJ, et al. Immature teratoma of the ovary with a neural component ('solid' teratoma): a clinicopathologic study of 20 cases. Hum Pathol 1976;7:625-642.

6 Peterson WF. Malignant degeneration of benign cystic teratoma of the ovary: collective review of the literature. Obstet Gynecol Survey 1957;12:793-830.

7 Climie ARW, Heath LP. Malignant degeneration of benign cystic teratoma of the ovary. Cancer 1968; 22:824-832.

8 Kurman RJ, Norris HJ. Malignant mixed germ cell tumors of the ovary: a clinical and pathologic analysis of 30 cases. Obstet Gynecol 1976;48:579-589.

9 Linder D, McCaw BK, Hecht F. Parthenogenetic origin of benign ovarian teratomas. N Engl J Med 1975;292: 63-66.

10 Vortmeyer AO, Devouassoux-Shisheboran M, Li G, et al. Microdissection-based analysis of mature ovarian teratoma. Am J Pathol 1999;154:987-991.

11 Kraggerud SM, Szymanska J, Abeler VM, et al. DNA copy number changes in malignant ovarian germ cell tumors. Cancer Res 2000;60:3025-3030.

12 van Echten J, van Doorn JC, van der Linden HC, et al. Cytogenetics of a malignant ovarian germ-cell tumor. Int J Cancer 1998;77:217-218.

13 Coventry S, Punnett HH, Tomczak EZ, et al. Consistency of isochromosome $7 \mathrm{q}$ and trisomy 8 in hepatosplenic gamma/delta T-cell lymphoma: detection by fluorescence in situ hybridization of a splenic touchpreparation from a pediatric patient. Pediatr Dev Pathol 1999;2:478-483.

14 Meng FJ, Zhou Y, Giwercman A, et al. Fluorescence in situ hybridization analysis of chromosome 12 anomalies in semen cells from patients with carcinoma in situ of the testis. J Pathol 1998;186:235-239.

15 Velagaleti GV, Tapper JK, Rampy BA, et al. A rapid and noninvasive method for detecting tissue-limited mosaicism: detection of $\mathrm{i}(12)(\mathrm{p} 10)$ in buccal smear from a child with Pallister-Killian syndrome. Genet Test 2003;7:219-223.

16 Kernek KM, Brunelli M, Ulbright TM, et al. Fluoresence in situ hybridization analysis of chromosome $12 p$ in paraffin-embedded tissue is useful for establishing germ cell origin in metastatic tumors. Mod Pathol 2004;17:1309-1313.

17 Ulbright TM. Germ cell tumors of the gonads: a selective review emphasizing problems in differential diagnosis, newly appreciated, and controversial entities. Mod Pathol 2005;18(Suppl 2):S61-S79.
18 Manivel JC, Reinberg Y, Niehans GA, et al. Intratubular germ cell neoplasia in testicular teratomas and epidermoid cysts. Cancer 1989;64:715-720.

19 Atkin NB, Baker MC. i(12p): specific chromosomal marker in seminoma and malignant teratoma of the testis? Cancer Genet Cytogenet 1983;10:199-204.

20 Castedo SM, de Jong B, Oosterhuis JW, et al. Chromosomal changes in mature residual teratomas following polychemotherapy. Cancer Res 1989;49:672-676.

21 Gibas Z, Prout GR, Pontes JE, et al. Chromosome changes in germ cell tumors of the testis. Cancer Genet Cytogenet 1986;19:245-252.

22 Oosterhuis JW, de Jong B, Cornelisse CJ, et al. Karyotyping and DNA flow cytometry of mature residual teratoma after intensive chemotherapy of disseminated nonseminomatous germ cell tumor of the testis: a report of two cases. Cancer Genet Cytogenet 1986;22:149-157.

23 Rodriguez E, Mathew S, Reuter V, et al. Cytogentic analysis of 124 prospectively ascertained male germ cell tumors. Cancer Res 1993;52:2285-2291.

24 Looijenga LH, Oosterhuis JW, Ramaekers FC, et al. Dual parameter flow cytometry for deoxyribonucleic acid and intermediate filament proteins of residual mature teratoma all tumor cells are aneuploid. Lab Invest 1991;64:113-117.

25 Kernek KM, Ulbright TM, Zhang S, et al. Identical allelic losses in mature teratoma and other histologic components of malignant mixed germ cell tumors of the testis. Am J Pathol 2003;163:2477-2484.

26 Simmonds PD, Lee AH, Theaker JM, et al. Primary pure teratoma of the testis. J Urol 1996;155:939-942.

27 Sesterhenn IA, Mesonero C, Davis CJ, et al. Testicular teratomas in adults [abstract]. Histopathology 2002; 41(Suppl 1):24.

28 Leibovitch I, Foster RS, Ulbright TM, et al. Adult primary pure teratoma of the testis: the Indiana experience. Cancer 1995;75:2244-2250.

29 Stock C, Ambros IM, Lion T, et al. Detection of numerical and structural chromosomal abnormalities in pediatric germ cell tumors by means of interphase cytogenetics. Genes Chromosomes Cancer 1994;11:40-50.

30 Bussey KJ, Lawce HJ, Olson SB, et al. Chromosome abnormalities of eighty-one pediatric germ cell tumors: sex-, age-, site-, and histopathology-related differences-a children's cancer group study. J Urol 1999; 168:134-146.

31 Mostert M, Rosenberg C, Stoop H, et al. Comparative genomic and in situ hybridization of germ cell tumors of the infantile testis. Lab Invest 2000;80:1055-1064.

32 Baker BA, Frickey L, Yu I, et al. DNA content of ovarian immature teratomas and malignant germ cell tumors. Gynecol Oncol 1998;71:14-18.

33 Surti U, Hoffner L, Chakravarti A, et al. Genetics and biology of human ovarian teratomas. i. cytogenetic analysis and mechanism of origin. Am J Hum Genet 1990;47:635-643. 